\title{
Auranofin in the treatment of steroid dependent asthma: a double blind study
}

\author{
G Nierop, W P Gijzel, E H Bel, A H Zwinderman, J H Dijkman
}

\begin{abstract}
Background Long term administration of oral corticosteroids in patients with asthma may be associated with serious side effects. Non-steroidal anti-inflammatory drugs, including gold salts, have been shown to reduce the need for systemic corticosteroid treatment in uncontrolled studies. The effect of oral gold (auranofin) on asthma symptoms, lung function, and the need for oral prednisone treatment was investigated.

Methods A 26 week randomised, double blind, placebo controlled, parallel group trial of auranofin was performed in 32 patients with moderately severe chronic asthma who required an oral corticosteroid dose of at least $5 \mathrm{mg}$ prednisone a day (or equivalent) or $2.5 \mathrm{mg} /$ day prednisone plus more than $800 \mu \mathrm{g} /$ day inhaled corticosteroids. Auranofin was given orally in a dose of $3 \mathrm{mg}$ twice daily. Asthma symptoms, lung function, and adverse effects were assessed at regular intervals. After 12 weeks of treatment prednisone dosage was tapered down by $2.5 \mathrm{mg}$ every two weeks if the patient was clinically stable. Asthma exacerbations were treated with short courses of high doses of oral steroids.
\end{abstract}

Results Twenty eight of the 32 patients, 13 in the placebo group and 15 in the auranofin group, completed the study. The total corticosteroid reduction achieved after 26 weeks of treatment was significantly greater (4 mg) in the auranofin group than in the placebo group ( $0.3 \mathrm{mg})$. The number of exacerbations requiring an increase of steroids was greater in the placebo group $(2 \cdot 1)$ than in the active group (0.9). A significant increase in $\mathrm{FEV}_{1}$ of $6.4 \%$ predicted occurred in the auranofin group during the study and there was a reduction of asthma symptoms such as wheezing and cough. There was no difference between the groups in peak flow measurements or in the number of asthma attacks. The incidence of side effects of auranofin was low, but exacerbations of constitutional eczema were noticeable.

Conclusion Auranofin provides an effective adjunct to treatment for steroid dependent asthma, leading to a reduction of oral steroid dose.

Airway inflammation plays a major part in the pathogenesis of bronchial hyperresponsiveness and asthma. ${ }^{12}$ Topical drugs with anti- inflammatory activity, such as inhaled corticosteroids, sodium cromoglycate, and nedocromil sodium, are being prescribed on a large scale to all types of asthmatic patients. ${ }^{34}$ These drugs improve asthma symptoms, ${ }^{5-7}$ prevent the increase in bronchial responsiveness after inhalation of allergen, ${ }^{8}$ and reduce bronchial hyperresponsiveness in allergic and non-allergic patients with asthma of mild to moderate severity. ${ }^{910}$ Some asthmatic patients, however, are refractory to even high doses of topical anti-inflammatory drugs and require systemic anti-inflammatory treatment. Oral and intravenous glucocorticosteroids are still considered the most effective treatment for severe asthma, ${ }^{11}$ but their long term administration may be associated with serious and sometimes irreversible side effects. ${ }^{1213}$

In some chronic inflammatory diseases, such as rheumatoid arthritis, other types of systemic anti-inflammatory drugs or steroid sparing agents,. including gold salts and methotrexate, have been used. ${ }^{14}$ Parenteral gold salts have been used to treat asthma for some time in Japan, with symptomatic improvement and a reduced need for corticosteroids. ${ }^{1516}$ Some evidence of a benefit from oral gold treatment was reported in two Amierican studies on patients with steroid dependent asthma, ${ }^{17} 18$ a steroid sparing effect ${ }^{1718}$ and reduction in airway hyperresponsiveness to methacholine ${ }^{18}$ being observed after 16-22 weeks of treatment. A comparative study of auranofin (oral gold) and parenteral gold has shown that the withdrawal rate due to adverse reactions was twice as high with parenteral gold. ${ }^{19}$ Although the precise mechanism of action of auranofin is unknown, its effects are likely to be due to its anti-inflammatory and immunoregulatory activity. ${ }^{2021}$

Oral gold may therefore modulate the immune response in asthma and reduce the inflammatory process in the airway wall, thereby attenuating asthma symptoms and reducing the need for systemic corticosteroid treatment. The effect of auranofin on asthma symptoms, lung function, and the requirement for concomitant treatment was therefore investigated.

\section{Methods}

SUBJECTS

Thirty two adults (17 male, 15 female), mean age 52.4 (range 28-72) years, with a diagnosis of moderately severe asthma ${ }^{22}$ were recruited from the outpatient clinic of the department of pulmonary diseases of the Leiden University Hospital. All patients gave informed consent to participating in the study, which was 
Table 1 Characteristics of the subjects

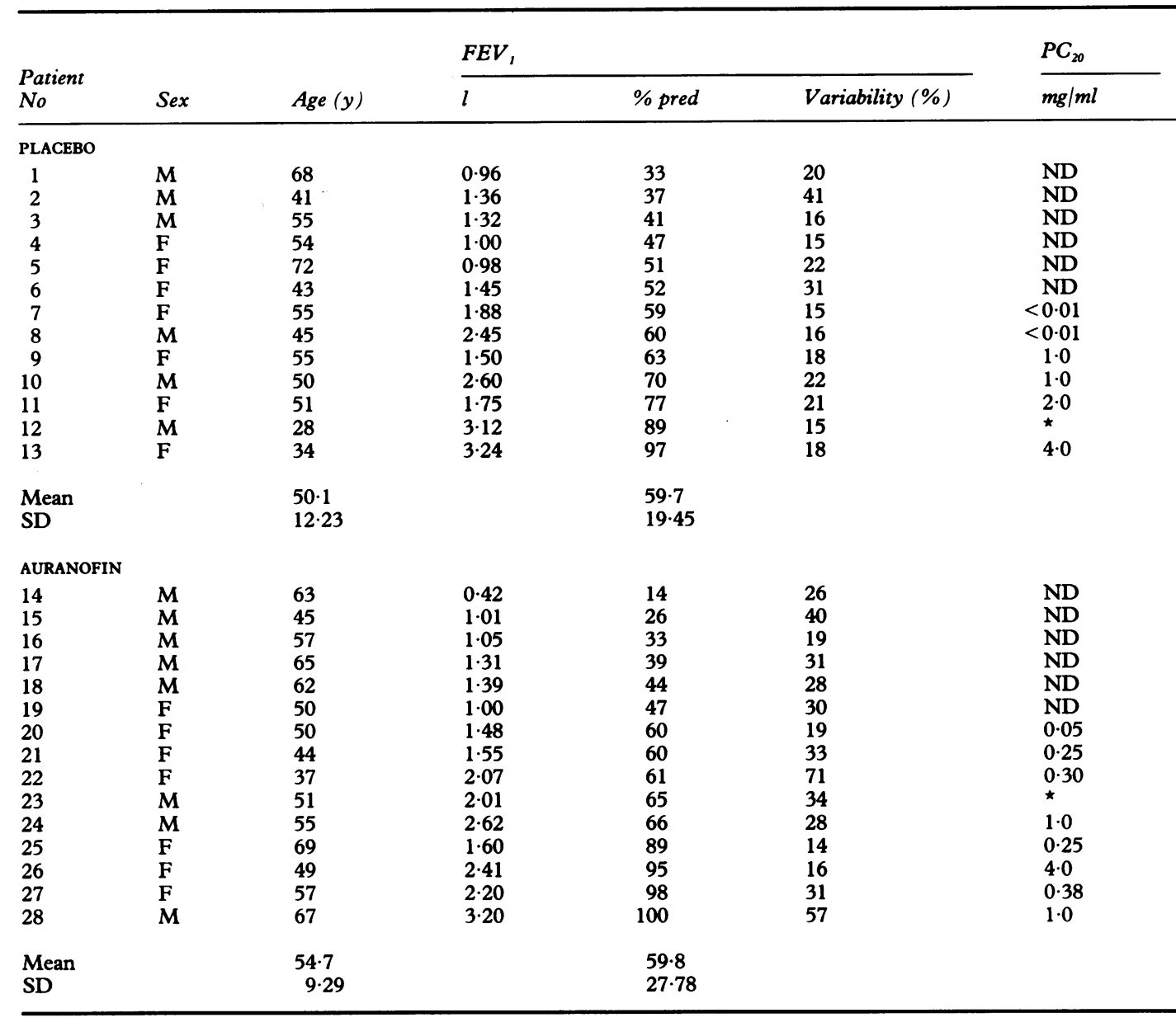

«Test not understood because of language difficulties.

approved by the hospital ethics committee. Table 1 summarises the subjects' characteristics at their entry into the study. All patients had a history of episodic cough, dyspnoea, and wheezing, which had lasted from two to 40 years. Mean baseline $\mathrm{FEV}_{1}$ was $59 \cdot 7 \%$ (range 33-97\%) of the predicted value ${ }^{23}$ in the placebo group and $59.8 \%(14-100 \%)$ in the auranofin group. In all subjects $400 \mu \mathrm{g}$ of inhaled salbutamol caused a rise in $\mathrm{FEV}_{1}$ of at least $15 \%$. In subjects with an $\mathrm{FEV}_{1}$ of more than $1500 \mathrm{ml}$ a challenge test with inhaled histamine was performed. In these subjects the provocative concentration causing a $20 \%$ fall in $\mathrm{FEV}_{1}$ was less than $8 \mathrm{mg} / \mathrm{ml}^{24}$ Three subjects in the placebo group and seven subjects in the auranofin group were atopic as shown by a positive response to 13 common allergens in the radioallergosorbent test (RAST). Fifteen patients were lifelong nonsmokers, 11 were ex-smokers (having stopped smoking at least 12 months previously), and two were current smokers. All except three patients were receiving inhaled corticosteroids, at least $800 \mu \mathrm{g} /$ day. The individual dose of inhaled steroids remained constant during the study. Three patients could not tolerate topical corticosteroids because of side effects (cough and dyspnoea after inhalation). All patients had required at least $2.5 \mathrm{mg}$ oral prednisone a day for at least one year before entering the study (mean duration $7 \cdot 8$ (range $1-35$ ) years in the placebo group and 6 (range 1-18) years in the auranofin group).
PULMONARY FUNCTION

Measurements of $\mathrm{FEV}_{1}$ and vital capacity were performed with a dry rolling seal spirometer (Mijnhardt Volugraph 2000). Inhaled bronchodilators were discontinued for eight and long acting theophyllines for 12 hours before testing. Peak flow rates were measured with a mini Wright peak flow meter (Airmed, London) in the daytime (on waking) and at night (just before bedtime). The best of three readings was recorded.

STUDY DESIGN

The study had a parallel group, double blind and placebo controlled design. The study consisted of a pretreatment baseline period of one week and a treatment period of 26 weeks. Baseline assessments during the pretreatment period included a medical history, a physical examination, and laboratory tests (full blood count, platelet count, serum biochemistry and urine analysis). The patients were given a diary card to record asthma symptoms (wheezing, breathlessness, chest tightness, cough), exacerbations on a 0-4 scale, and peak expiratory flow (PEF) during both day and night. At the end of the pretreatment period (day 0) spirometry was performed and symptom scores for the preceding seven days were added to form a baseline symptom score. On day 0 the patients were randomly allocated to two parallel treatment groups, receiving either auranofin or placebo. They received either auranofin $3 \mathrm{mg}$ (Smith Kline Beecham 


\begin{tabular}{|c|c|c|c|c|c|c|}
\hline \multirow[b]{2}{*}{$R A S T$} & \multirow[b]{2}{*}{$\begin{array}{l}\text { Smoking } \\
\text { history }\end{array}$} & \multirow{2}{*}{$\begin{array}{l}\text { Duration } \\
\text { of } \\
\text { asthma } \\
\text { (months) }\end{array}$} & \multirow[b]{2}{*}{$\begin{array}{l}\text { ICS } \\
\text { (mg/day) }\end{array}$} & \multicolumn{2}{|c|}{ Prednisolone } & \multirow[b]{2}{*}{$\begin{array}{l}\text { Other } \\
\text { drugs }\end{array}$} \\
\hline & & & & $\begin{array}{l}\text { Dose } \\
\text { (mg/day) }\end{array}$ & $\begin{array}{l}\text { Months of } \\
\text { treatment }\end{array}$ & \\
\hline _- & Ex & 36 & 2000 & 5 & 30 & abt \\
\hline - & Ex & 300 & 1600 & 15 & 96 & abct \\
\hline - & + & 180 & 800 & 5 & 72 & ab \\
\hline+ & Ex & 84 & None & $7 \cdot 5$ & 60 & bt \\
\hline - & - & 300 & 800 & 10 & 300 & bh \\
\hline - & Ex & 24 & 800 & 5 & 18 & bt \\
\hline+ & - & 120 & 1000 & 10 & 18 & bt \\
\hline- & Ex & 120 & 2400 & 12.5 & 72 & bt \\
\hline - & Ex & 480 & 1000 & 5 & 420 & abt \\
\hline - & - & 120 & 1000 & 7.5 & 48 & bc \\
\hline - & - & 240 & None & 10 & 12 & abt \\
\hline+ & - & 240 & 2000 & 20 & 36 & abt \\
\hline - & Ex & 36 & 800 & 10 & 36 & t \\
\hline $\begin{array}{l}\text { Mean } \\
\text { SD }\end{array}$ & & $\begin{array}{l}175 \cdot 4 \\
132 \cdot 77\end{array}$ & & $\begin{array}{l}9 \cdot 4 \\
4 \cdot 47\end{array}$ & $\begin{array}{c}93 \cdot 7 \\
123 \cdot 17\end{array}$ & \\
\hline & & & & & & \\
\hline - & \pm & $\begin{array}{l}120 \\
192\end{array}$ & $\begin{array}{l}1200 \\
1600\end{array}$ & $\begin{array}{l}5 \\
7.5\end{array}$ & $\begin{array}{r}24 \\
120\end{array}$ & $\begin{array}{l}a b t \\
b\end{array}$ \\
\hline+ & - & 480 & None & 15 & 84 & b \\
\hline+ & - & 660 & 800 & $7 \cdot 5$ & 12 & bct \\
\hline $\begin{array}{l}\mathrm{T} \\
-\end{array}$ & Ex & 36 & 2000 & 5 & 30 & bht \\
\hline _- & - & 120 & 800 & $2 \cdot 5$ & 120 & bc \\
\hline - & Ex & 540 & 1600 & 5 & 18 & abt \\
\hline+ & - & 360 & 1000 & 2.5 & 24 & bct \\
\hline+ & - & 240 & 1000 & 6.3 & 192 & bt \\
\hline+ & - & 18 & 1600 & 15 & 12 & abt \\
\hline- & - & 120 & 800 & 2.5 & 60 & - \\
\hline - & Ex & 60 & 800 & 2.5 & 10 & bt \\
\hline+ & - & 96 & 1600 & $7 \cdot 5$ & 36 & bt \\
\hline+ & - & 420 & 1600 & 5 & 24 & bcht \\
\hline- & Ex & 216 & 2000 & 10 & 216 & bht \\
\hline $\begin{array}{l}\text { Mean } \\
\text { SD }\end{array}$ & & $\begin{array}{l}245 \cdot 2 \\
200 \cdot 09\end{array}$ & & $\begin{array}{l}7 \cdot 6 \\
5 \cdot 31\end{array}$ & $\begin{array}{l}65.5 \\
67 \cdot 25\end{array}$ & \\
\hline
\end{tabular}

RAST-radioallergosorbent test; a-anticholinergic; b- $\boldsymbol{\beta}_{2}$-agonist; $\mathrm{c}$-cromoglycate; a-antihistamine; $t$-theophylline; ICS - inhaled corticosteroids.

Laboratories, Philadelphia) once a day for the first two weeks and then $3 \mathrm{mg}$ twice a day for the following 24 weeks, or matched placebo for the 26 weeks. Regular asthma drugs, including inhaled broncho-dilators and theophyllines, were continued in the usual dosage during the trial.

The patients visited the hospital every two weeks for physical examination and assessment of symptoms, their need for other medication, and side effects. All were seen by the same physician (GN) throughout the study. Blood tests were repeated every two weeks for the first 10 weeks and every four weeks for the remainder of the study. Spirometry was carried out after 12 and 26 weeks of treatment. If after 12 weeks' treatment the patient was clinically stable according to the diary card, symptoms, and spirometric results, oral prednisone was tapered down by $2.5 \mathrm{mg}$ at each two weekly visit. When clinical deterioration occurred oral corticosteroid treatment was intensified temporarily (prednisone $25 \mathrm{mg} /$ day, tapered down by $5 \mathrm{mg} /$ day every two days) and often an antibiotic was added. The decision to increase the steroid dose was made by the investigator physician on clinical criterianamely, symptoms of an upper respiratory tract infection with pyrexia, increase in asthma symptoms (wheezing, breathlessness, chest tightness, cough), no sustained response after inhalation of bronchodilators, or a decrease in mean daytime or night-time peak flow of at least $10 \%$ over the previous seven days. At the end of the treatment period there was a final physical examination and laboratory test and a global assessment by the physician of the efficacy of the treatment.

\section{ADVERSE REACTIONS}

All adverse reactions observed by the investigator or reported by the patient were recorded. Haematological abnormalities were considered significant if there was a fall in the platelet count of more than $100 \times 10^{9} / 1$ or leucopenia (leucocytes $<3.0 \times 10^{9} / 1$ ). Repeated proteinuria $(1+$ proteinuria on more than one occasion) was considered to be a serious adverse reaction. When gastrointestinal symptoms such as diarrhoea occurred, the dose of auranofin was temporarily reduced to $3 \mathrm{mg}$ daily for up to two weeks. The auranofin dose was increased to $3 \mathrm{mg}$ twice daily once the symptoms had resolved. When eczema became worse a topical low grade corticosteroid ointment or an oral antihistamine drug (or both) was started. Patients with extensive persistent eczema resistant to treatment were withdrawn from the study.

\section{STATISTICAL ANALYSIS}

Differences between patients receiving auranofin and placebo were tested by the MannWhitney $U$ test and the $\chi^{2}$ test. Differences in changes over time between the auranofin and the placebo group were tested by repeated measures analysis of variance with week number as a covariate. As steroid use was irregular, change in steroid use with time was characterised by the Spearman rank correlation coefficient, calculated for each patient and averaged for the patients receiving auranofin and placebo.

As we had a sample of 13 subjects in each group and knew the standard deviation of the differences in daily prednisone dosage in the placebo group $(5.2 \mathrm{mg})$, the power of the analysis was 0.8 (beta $=0.2$ ) to detect a change greater than $5.0 \mathrm{mg}$ prednisone/day when $\alpha=0.05$ (one tailed).

Table 2 Daily prednisone dose at week 0 and week 26 for each individual

\begin{tabular}{|c|c|c|c|c|c|}
\hline \multicolumn{3}{|l|}{ Placebo } & \multicolumn{3}{|c|}{ Auranofin } \\
\hline $\begin{array}{l}\text { Patient } \\
\text { No }\end{array}$ & Week 0 & Week 26 & $\begin{array}{l}\text { Patient } \\
\text { No }\end{array}$ & Week 0 & Week 26 \\
\hline $\begin{array}{r}1 \\
2 \\
3 \\
4 \\
5 \\
6 \\
7 \\
8 \\
9 \\
10 \\
11 \\
12 \\
13\end{array}$ & $\begin{array}{c}5 \\
20 \\
5 \\
5 \\
15 \\
5 \\
10 \\
15 \\
5 \\
10 \\
7 \cdot 5 \\
20 \\
10\end{array}$ & $\begin{array}{c}0 \\
15 \\
0 \\
5 \\
20 \\
0 \\
15 \\
20 \\
2 \cdot 5 \\
10 \\
10 \\
20 \\
10\end{array}$ & $\begin{array}{l}14 \\
15 \\
16 \\
17 \\
18 \\
19 \\
20 \\
21 \\
22 \\
23 \\
24 \\
25 \\
26 \\
27 \\
28\end{array}$ & $\begin{array}{c}10 \\
5 \\
15 \\
10 \\
20 \\
2 \cdot 5 \\
5 \\
20 \\
6 \cdot 3 \\
10 \\
2 \cdot 5 \\
2 \cdot 5 \\
10 \\
5 \\
10\end{array}$ & $\begin{array}{c}15 \\
2 \cdot 5 \\
7 \cdot 5 \\
5 \\
20 \\
0 \cdot 5 \\
10 \\
5 \\
1 \cdot 4 \\
0 \\
0 \\
0 \\
0 \\
0 \\
5\end{array}$ \\
\hline $\begin{array}{l}\text { Mean } \\
\text { SD }\end{array}$ & $\begin{array}{l}11 \\
6.35\end{array}$ & $\begin{array}{c}10 \cdot 7 \\
7 \cdot 33\end{array}$ & & $\begin{array}{l}9 \cdot 3 \\
6 \cdot 34\end{array}$ & $\begin{array}{l}5 \cdot 3 \\
6 \cdot 19\end{array}$ \\
\hline
\end{tabular}




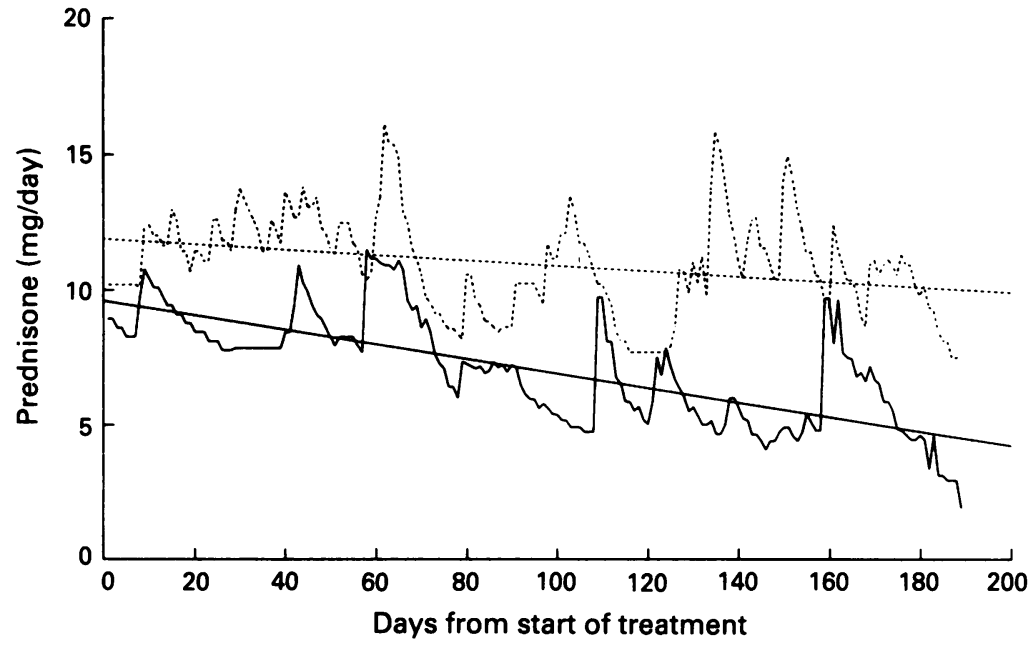

Figure 1 Mean daily dose of oral corticosteroids during the study in the placebo group (dotted lines) and in the auranofin group (continuous lines).

\section{Results}

Of the 32 patients, 28 completed the 26 week trial. One patient (placebo group) was withdrawn because of non-compliance with the protocol and three (two in the auranofin and one in the placebo group) because of serious eczema, resistant to topical treatment and antihistamines. Of the 28 evaluable patients, 15 received auranofin and 13 placebo. There were no significant differences in sex, age, atopic status, proportion of smokers and ex-smokers, duration of asthma, or duration of corticosteroid dependency between the two groups (table 1).

\section{REDUCTION OF ORAL CORTICOSTEROIDS}

There was no difference in the mean daily dose of prednisone between the two groups on entry into the study $(p=0 \cdot 17)$. The mean change in the mean daily dose of oral corticosteroids is shown in figure 1 . The pattern of steroid use was very irregular, but there was a reduction with time in both groups. The reduction was greater in the auranofin group than in the placebo group, the mean Spearman rank correlation coefficient (SE) between day number and daily steroid dose being $-0.54(0.43)$ in the

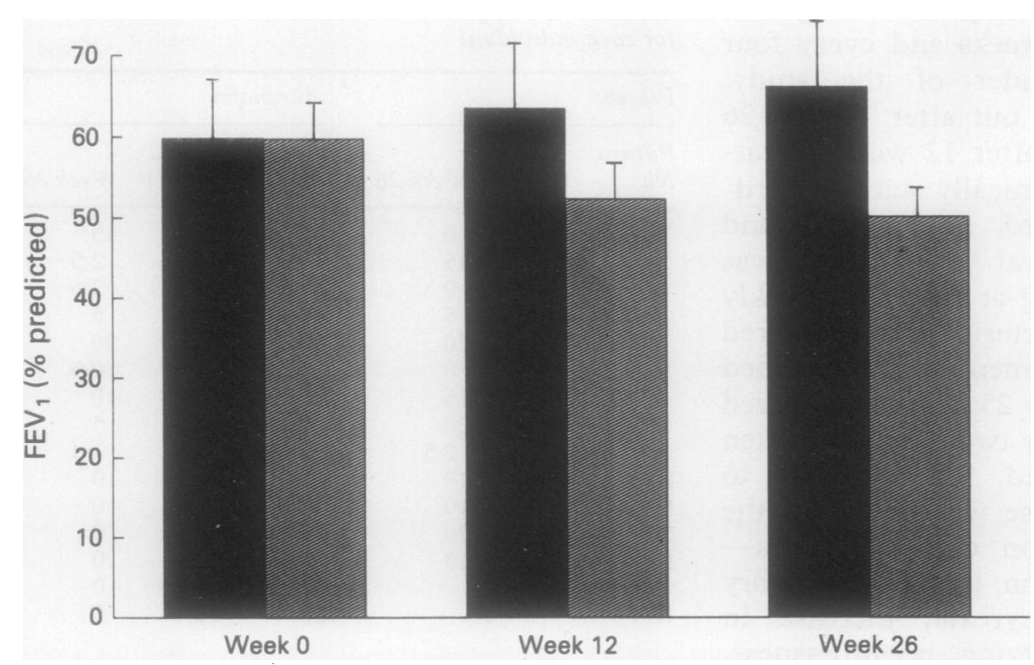

Figure 2 Mean values for $F E V,(S E)$ measured in weeks 1, 12, and 26 in the placebo group (hatched columns) and in the auranofin group (solid columns). auranofin group and $-0.22(0.47)$ in the placebo group ( $p=0.036$ ). When the mean (SD) daily steroid doses for the first two weeks and the last two weeks of treatment were compared, there was a reduction from 9.3 (6.34) to $5.3(6 \cdot 19) \mathrm{mg}$ in the auranofin group ( $p=0.007$ ) but no significant reduction in the placebo group (from $11.0(6.35)$ to 10.7 (7.33) mg; $p=0.48)$. The difference between the two groups, however, was not quite significant $(p=0.056)$. Five of the 15 patients in the auranofin group and three of the 13 patients in the placebo group were able to discontinue prednisone completely before the end of the study. At the end of the study all patients having active treatment but only three patients having placebo treatment preferred to continue their new medication.

\section{HIGH DOSE PREDNISONE COURSES}

The mean (SD) number of courses of high doses of oral steroids during the study was lower for the auranofin group (0.9 (1.22)) than for the placebo group $(2 \cdot 1(1 \cdot 66) ; p=0.02)$.

\section{LUNG FUNCTION}

There was no significant difference in FEV between the two groups on entry into the study $(p=0.93)$. Values for $F E V_{1}$ measured in weeks 1,12 , and 26 are shown in figure 2. Mean (SE) $\mathrm{FEV}_{1}$ as \% predicted increased from 59.8 $(26.8)$ to $66.2(29.6)$ in the auranofin group and decreased from $59.7(19.45)$ to $50.2(14.0)$ in the placebo group. The mean (SD) slopes of the regression lines between week number and FEV 1 were significantly different between the two groups, being $0.25(0.03)$ and $-0.36(0.13)$ respectively $(\mathrm{p}<0.0001)$.

\section{DIARY CARD ANALYSIS}

\section{Peak flow measurements}

Daytime and night time peak flow measurements over time are shown in figure 3. There were no significant changes in daytime or night time peak flow measurements over time within the two groups ( $p>0.94$ ), nor were there significant differences in peak flow changes over time between the groups (daytime $p>0 \cdot 19$; night time $\mathrm{p}>0.48$ ).

\section{Asthma symptoms}

The number of days and nights per week with wheezing and the severity of coughing score during the day and during the night are shown in figure 4. The mean number of days and nights per week with wheezing did not change over time in the placebo group ( $p<0.24$ and $<0.41$ ), but decreased from 4.6 to 3.4 days/ week and from 4.3 to 3.4 nights/week in the auranofin group ( $p<0.0002)$. The changes were significantly different between the two groups $(p<0.02$ and $<0.04)$. The severity of daytime and night time coughing (calculated as the cumulative daily score (0-4) during the week before each visit) did not change significantly over time in the auranofin group (from 5.1 to 4.4 during the day $(p>0.16)$ and 4.0 to 4.7 during the night $(p>0.06))$. In the placebo group there was an increase from 4.8 to 9.3 during the day $(p=0.03)$ and from 6.8 to 10.9 during the night $(p=0.0002)$. The changes 


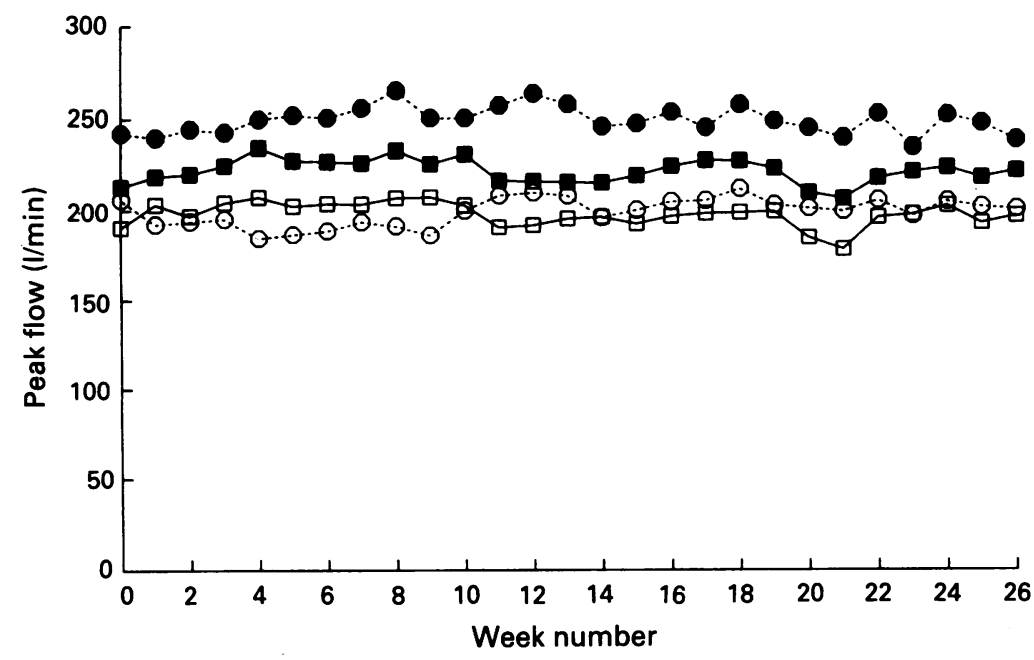

Figure 3 Mean values for daytime (open symbols) and night time (closed symbols) peak flow measurements in the placebo group (continuous lines) and the auranofin group (dotted lines). differed significantly between the two groups $(p=0.01$ and 0.02$)$. There were no significant changes over time in number of days per week with breathlessness or chest tightness.

\section{Number of asthma attacks}

The number of asthma attacks decreased with time in both groups, with a slight trend in favour of the auranofin group $(p=0.04)$. There
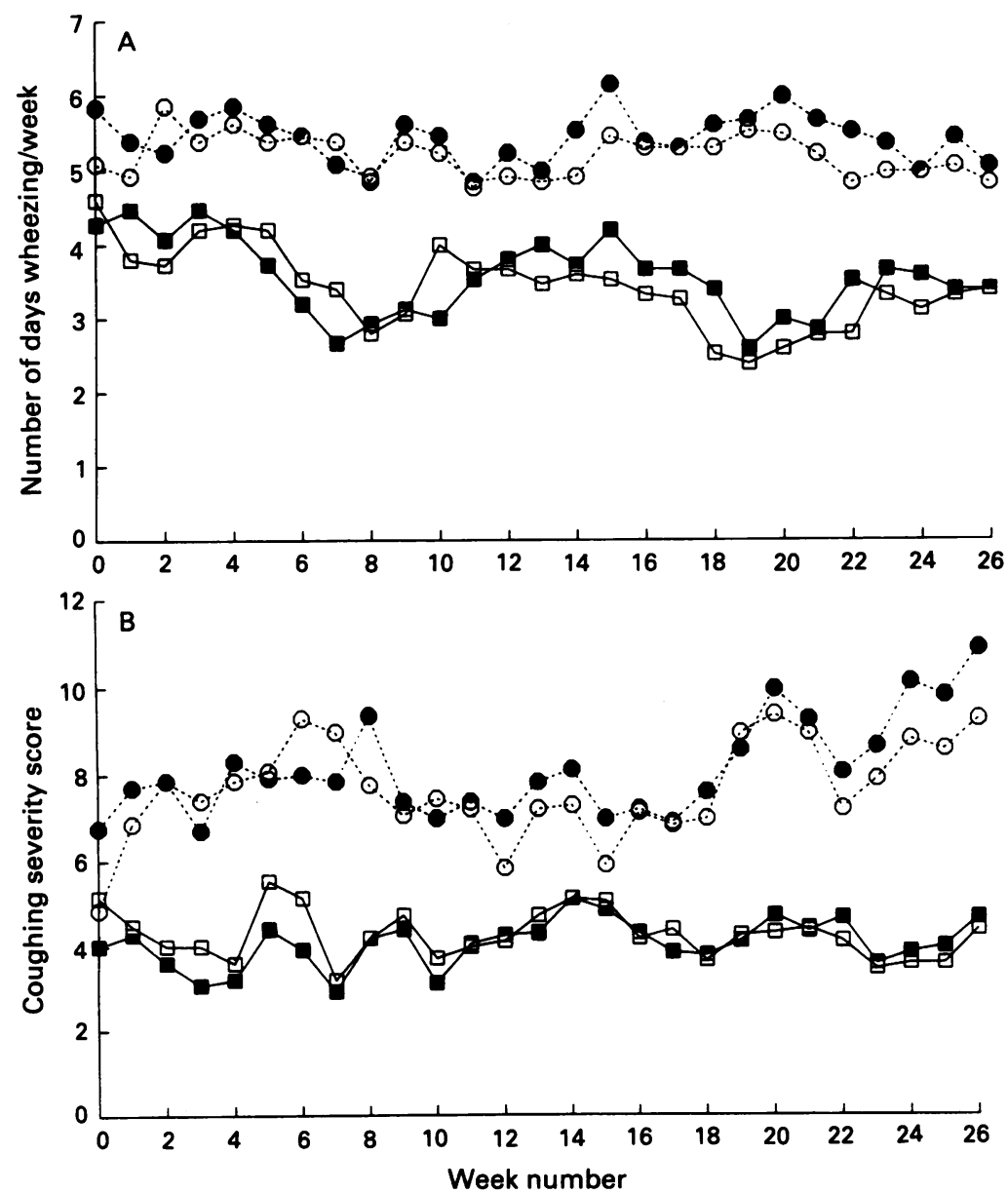

Figure 4 A-Mean number of days (open symbols) and nights (closed symbols) with wheezing in the placebo group (circles, dotted lines) and in the auranofin group (squares, wheezing in the placebo group (circles, dotted lines) and in the auranofin group (squares, symbols) and nights (closed symbols) in the placebo group (circles, dotted lines) and in the auranofin group (squares, continuous lines) during the study. was no difference between the groups in the duration of the attacks $(p=0.56)$.

\section{SUBJECTIVE ASSESSMENTS}

The physicians' global assessment rated the condition of 11 of the 15 patients in the auranofin group as being improved, compared with three of the 13 patients in the placebo group $(p=0.02)$.

\section{ADVERSE REACTIONS}

Apart from the two patients having auranofin who were withdrawn because of serious and resistant eczema, two further patients receiving auranofin developed transient mild eczema, with a good response to symptomatic treatment. They were able to continue auranofin in the normal dose. Nausea (three patients) and diarrhoea (one patient) occurred in patients taking auranofin and improved with reduction of the auranofin dose to $3 \mathrm{mg} /$ day for two weeks. No significant changes in haematological or serum biochemical measurements or urine analysis were observed.

\section{Discussion}

The present study shows that oral gold (auranofin) reduces the daily requirement of oral corticosteroids and improves baseline $\mathrm{FEV}_{1}$ in steroid dependent asthmatic patients. The auranofin group had fewer exacerbations requiring short courses of high dose steroids than the placebo group. There was an improvement of asthma symptoms such as wheezing and cough, and the physicians' assessment was in favour of auranofin. These results suggest that auranofin may be helpful in patients who require oral corticosteroids.

This is the first placebo controlled study to show that oral gold has steroid sparing activity in steroid dependent asthmatic patients. It confirms and extends the results of previous studies on the efficacy of gold injections (chrysotherapy) in asthma, ${ }^{15}$ and of two uncontrolled studies on the steroid sparing effect of oral auranofin. ${ }^{17}{ }^{18}$ In contrast to the patients in these studies, most of our patients had asthma with non-allergic features. In addition, our patients had on average had asthma for longer and had lower baseline $\mathrm{FEV}_{1}$ values. We could not assess changes in airway responsiveness in these patients, because in most their $\mathrm{FEV}_{1}$ was too low for them to have an inhalation provocation test. The severity and instability of the disease in our patients, who had fairly "brittle" asthma, caused some difficulty in the analysis. Short courses of high doses of oral prednisone were frequently indicated for exacerbations in addition to the maintenance doses. These short courses interfered with the linear relation between steroid dose and time, and might have influenced the results negatively. Despite this, both the number of exacerbations and the maintenance dosage of steroids were reduced in the auranofin group.

The mode of action of auranofin in asthma is largely unknown, but various relevant pharmacological activities have been defined. Auranofin possesses anti-inflammatory and immunoregulatory activity. ${ }^{20}$ It affects acute 
and chronic inflammatory events, and inhibits tissue damaging events, such as lysosymal enzyme release, ${ }^{25}$ superoxide release from phagocytic cells, ${ }^{26}$ and antibody dependent cellular cytotoxicity. ${ }^{20}$ Auranofin inhibits cutaneous anaphylaxis reactions in rats ${ }^{27}$ and reduces the anti-IgE induced release of histamine in human basophils ${ }^{28}$ and the calcium ionophore induced formation of arachidonic acid metabolites by human neutrophils, basophils, and mast cells. ${ }^{29-31}$ Auranofin also inhibits polymorphonuclear leucocyte chemotaxis, ${ }^{32}$ aggregation, ${ }^{33}$ and phagocytosis. ${ }^{34}$ As asthma is characterised by an inflammatory process in the airways, ${ }^{12}$ these effects of auranofin may have dampened this process and may have added to the anti-inflammatory effects of oral corticosteroids.

There has been much concern about the side effects of long term systemic gold treatment. These include skin eruptions, stomatitis, proteinuria, microscopic haematuria, and haematological changes such as leucopenia and thrombocytopenia. ${ }^{19}$ In the present study the incidence of side effects attributed to auranofin was rather low. Two patients developed moderately severe eczema, resistant to symptomatic treatment. Gastrointestinal side effects disappeared after reduction of the auranofin dosage. Although the adverse effects of auranofin were not compared directly with the adverse effects of oral prednisone over the same period in our study, our data suggest a favourable risk-benefit ratio of auranofin treatment, as has been reported in other studies. ${ }^{18}$

The results of this study may have clinical implications. Our current understanding of the pathogenesis of asthma suggests that long term suppression of inflammation is the goal of asthma treatment. Inhaled anti-inflammatory drugs are usually effective, but in a few patients oral corticosteroids are necessary to control the disease. In view of the severity of the reported side effects of high dose steroid treatment, the minimal dose required to control asthma should be used. Auranofin $6 \mathrm{mg}$ daily for 26 weeks has a steroid sparing effect. The relatively mild side effects of auranofin appeared to be acceptable to most patients; only exacerbation of constitutional eczema was a serious problem. Our study suggests that the administration of auranofin in some patients with severe steroid dependent asthma may be justified. Studying the effect of auranofin in patients requiring higher doses of oral steroids and comparing auranofin with oral prednisolone over a longer period would be worthwhile.

1 Holgate ST, ed. The role of inflammatory processes in airway hyperresponsiveness. Oxford: Blackwell, 1989.

2 Barnes PJ. New concepts in the pathogenesis of bronchial hyper-responsiveness and asthma.J Allergy Clin Immuno 1989;83:1013-26.

3 Barnes PJ. A new approach to the treatment of asthma. $N$ Engl J Med 1989;321:1517-27.

4 McFadden ER. Corticosteroids and cromolyn sodium as modulators of airway inflammation. Chest 1988;94:181-4.

5 Eigen H, Reid JJ, Dahl R, Del Bufalo C, Fasano L, Gunella $G$, et al. Evaluation of the addition of cromolyn sodium to bronchodilator maintenance therapy in the long-term management of asthma. $J$ Allergy Clin Immunol 1987;80 612-21.

6 Thomson NC. Nedocromil sodium: an overview. Respir Med 1989;83:269-76.
7 Reed CE. Aerosol glucocorticoid treatment of asthma: adults. Am Rev Respir Dis 1990;141(suppl):S82-8.

8 Cockcroft DW, Murdock KY. Comparative effects of inhaled salbutamol, sodium cromoglycate, and beclomethasone dipropionate in allergen-induced early asthmatic responses, late asthmatic responses, and increased bronchia responsiveness to histamine. J Allergy Clin Immunol 1987; 79:734-40.

9 Barnes PJ. Effect of corticosteroids on airway hyperresponsiveness. Am Rev Respir Dis 1990;141(suppl):S70-6.

10 Bel EH, Timmers MC, Hermans J, Dijkman JH, Sterk PJ The long-term effects of nedocromil sodium and beclomethasone dipropionate on airway hyperresponsiveness to methacholine in non-atopic subjects. $A m R e v$ Respir Dis 1990;141:21-8.

11 Small P. Anti-inflammatory therapy in asthma. Ann Allergy 1989;62:481-2.

12 Kwong FK, Sue MA, Klaustermeyer WB. Corticosteroid complications in respiratory disease. Ann Allergy 1987; 58:326-30.

13 Truhan AP, Ahmed AR. Corticosteroids: a review with emphasis on complications of prolonged systemic therapy. Ann Allergy 1989;62:375-90.

14 Ward JR, Williams HJ, Egger MJ, Reading JC, Boyce E Altz-Smith $\mathrm{M}$, et al. Comparison of auranofin, gold sodium thiomalate, and placebo in the treatment of sodium thiomalate, and placebo in the treatment
rheumatoid arthritis. Arthr Rheum 1983;26:1303-15.

15 Muranaka M, Miyamoto T, Shida T, Kabe J, Makino S Okumura $\mathrm{H}$, et al. Gold salt in the treatment of bronchial asthma - a double blind study. Ann Allergy 1978;40: 132-7.

16 Muranaka M, Nakajima K, Suzuki S. Bronchial responsiveness to acetylcholine in patients with bronchial asthma after long-term treatment with gold salt. J Allergy Clin Immunol 1981;67:350-6.

17 Klaustermeyer WB, Noritake DT, Kwong FK. Chrysotherapy in the treatment of corticosteroid-dependent asthma. J Allergy Clin Immunol 1987;79:720-5.

18 Bernstein DI, Bernstein IL, Bodenheimer SS, Pietrusco RG. An open study of auranofin in the treatment of steroid-dependent asthma. J Allergy Clin Immunol 1988; 81:6-16.

19 Blodgett RC Jr, Pietrusco RG. Long-term efficacy and safety of auranofin: a review of clinical experience. Scand $J$ Rheumatol 1986;63(suppl):67-78.

20 Waltz DT, DiMartino MJ, Griswold DE, Intoccia AP, Flanagan TL. Biologic actions and pharmacokinetic studies of auranofin. Am J Med 1983;75(6A):90-108.

21 Snyder RM, Mirabelli CK, Crooke ST. The cellula pharmacology of auranofin. Semin Arthr Rheum 1987; 17:71-80.

22 American Thoracic Society. Standards for the diagnosis and care of patients with chronic obstructive pulmonary disease (COPD) and asthma. Am Rev Respir Dis 1987; disease (COP:225-44.

23 Quanjer $\mathrm{Ph} \mathrm{H}$, ed. Standardized lung function testing. Bull Eur Physiopathol Respir 1983;19(suppl 5):1-95.

24 Hargreave FE, Sterk PJ, Ramsdale EH, Dolovich J, Zame N. Inhalation challenge tests and airway responsiveness in man. Chest 1985;87:202-6S.

25 Dimartino MJ, Waltz DT. Inhibition of lysosomal enzyme release from rat leukocytes by auranofin. A new chrysotherapeutic agent. Inflammation 1977;2:131-42.

26 Roisman FR, Waltz DT, Finkelstein AE. Superoxide radical production by human leukocytes exposed to immune complexes: inhibitory action of gold compounds. Inflammation 1983;7:355-62.

27 Lewis AJ, Cottney J, White DD, Fox PK, McNeillie A Dunlop J, et al. Action of gold salts in some inflammatory and imm.

28 Takaishi T, Morita Y, Kudo K, Miyamoto T. Auranofin, an oral chrysotherapeutic agent, inhibits histamine release from human basophils. J Allergy Clin Immunol 1984;74: 296-301.

29 Marone G, Columbo M, Galeone D. Modulation of the release of histamine and arachidonic acid metabolites from human basophils and mast cells by auranofin. Agents Actions 1986;18:100-2.

30 Honda Z, Lisaza T, Morita Y, Matsuka K, Nishida Y, Miyamoto $T$. Differential inhibitory effects of auranofin on leukotriene $\mathrm{B}_{4}$ and leukotriene $\mathrm{C}_{4}$ formation by human polymorphonuclear leukocytes. Biochem Pharmacol 1987; 36:1475-81.

31 Parente J, Wong D, Davis P. Effects of gold components on leucotriene $B_{4}$, leucotriene $C_{4}$ and prostaglandin $E_{2}$ production by polymorphonuclear leucocytes. $J$ Rheumatol 1986;13:47-51.

32 Scheinberg MA, Santos LM, Finkelstein AE. The effect of auranofin and sodium aurothiomalate on peripheral blood monocytes. J Rheumatol 1982;9:366-9.

33 Wolach B, Deboard JE, Baehner RL, Boxer LA. Modulation of leukocyte aggregation and degranulation by gold compounds [abstract]. Fed Proc 1981;40:753.

34 Davis P, Miller C, Russell AS. Effects of gold compounds on the function of phagocytic cells. I. Suppression of phagocytosis and the generation of chemiluminescence by polymorphonuclear leukocytes. J Rheumatol 1982;9 (suppl 8):18-24. 